\title{
Assessment and monitoring of treatment response in adult ADHD patients: current perspectives
}

This article was published in the following Dove Press journal:

Neuropsychiatric Disease and Treatment

27 January 2017

Number of times this article has been viewed

\section{J Russell Ramsay}

Adult ADHD Treatment \& Research Program, Perelman School of

Medicine, University of Pennsylvania

Philadelphia, PA, USA

Video abstract

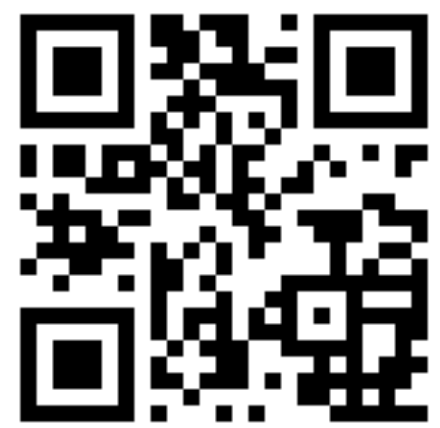

Point your SmartPhone at the code above. If you have a QR code reader the video abstract will appear. Or use:

http://youtu.be/kWzagCRPKxc
Correspondence: J Russell Ramsay Adult ADHD Treatment \& Research Program, Perelman School of Medicine, University of Pennsylvania, 3535 Market Street, \#2027, Philadelphia, PA 19104, USA

Tel +I 2I58984I07

Email ramsay@mail.med.upenn.edu
Abstract: Attention-deficit/hyperactivity disorder (ADHD) is a neurodevelopmental syndrome that emerges in childhood or early adolescence and persists into adulthood for a majority of individuals. There are many other adults with ADHD who may not seek out evaluation and treatment until adulthood, having been able to "get by" before struggling with inattention, hyperactivity, and/or impulsivity in adulthood, in addition to facing the associated features of disorganization, poor time management, and procrastination among many others. A lifetime diagnosis of ADHD is associated with a wide range of life impairments, which makes a comprehensive and accurate diagnostic assessment essential in order to obtain appropriate treatment. Moreover, while there are effective medical and psychosocial treatments for ADHD, it is important to be able to track treatment response in order to evaluate whether adjustments in specific interventions are needed or referrals for adjunctive treatments and supports are indicated to facilitate optimal therapeutic outcomes. The goal of this article is to provide a clinically useful review of the various measures that practicing clinicians can use to aid in the diagnostic assessment and monitoring of psychosocial and medical treatment of ADHD in adult patients. This review includes various structured interviews, screening scales, adult ADHD symptom inventories, measures of associated features of ADHD, as well as ratings of impairment and functioning which can be adapted to clinicians' practice needs in order to track treatment progress and optimize treatments for adults with ADHD

Keywords: adult attention-deficit/hyperactivity disorder, adult ADHD, pharmacotherapy, psychosocial treatment, symptoms, functional impairments, executive functions

\section{Assessment and monitoring of treatment response in adult ADHD patients: current perspectives}

Attention-deficit/hyperactivity disorder (ADHD) is a neurodevelopmental syndrome that is classified as a disorder usually first diagnosed in infancy, childhood, or adolescence. ${ }^{1}$ The international prevalence rates for ADHD in childhood fall around 3\% and generally within the 3\%-5\% range cited in the Diagnostic and Statistical Manual of Mental Disorders (DSM) fifth edition (DSM-5) when strict diagnostic guidelines are followed, with similar prevalence rates found for adults. ${ }^{1-4}$ Persistence rates for ADHD into adulthood for diagnosed children range from about $40 \%$ to upwards of $75 \%$ depending on the definition of persistence used. That is, the rates for full syndromatic persistence fall in the $36 \%-40 \%$ range using strict DSM criteria, whereas rates for symptomatic persistence with functional impairment are higher, falling at upwards of $80 \% .^{5-7}$

Although it was originally thought that the symptoms of ADHD would inexorably remit by late adolescence or young adulthood, various longitudinal studies have indicated that symptoms persist for a majority of individuals in either full syndromatic 
form or clinically significant residual form. ${ }^{7-9}$ A minority of individuals may experience symptomatic remission in adulthood. ${ }^{7,9} 10$ These longitudinal studies of individuals diagnosed with ADHD in childhood do not capture those individuals diagnosed in adolescence or adulthood, who exhibited symptoms of ADHD when they were younger but did not experience significant and sustained enough impairments compelling them to seek assessment and treatment until later in life. Cross-sectional studies of adults seeking assessment for ADHD have been conducted in order to identify the unique presentations of this clinical group first identified in adulthood. ${ }^{10,11}$ In fact, there have been recent studies examining the notion of adult-onset ADHD for individuals who were reportedly asymptomatic in childhood but then exhibited emergent symptoms in adulthood that met diagnostic thresholds. ${ }^{12-15}$ There are many cautions about rash conclusions from these emergent findings that will require follow-up studies to sort through. However, some initial conjectures from these studies are that the notion of ADHD as a neurodevelopmental syndrome might also suggest that chronological age of onset should not be a limiting diagnostic factor. That is, the onset of symptoms may occur later in life, or the presence of even minimal subthreshold symptoms in childhood may be a risk factor for later emergence, or childhood- and adult-onset ADHD are distinct syndromes which are not tied to neurodevelopment. ${ }^{15}$ For the time being, of clinical importance is that individuals with prominent features of ADHD face many life difficulties for which they seek treatment.

ADHD is one of the more impairing conditions encountered in outpatient clinical psychology and psychiatry practice. Numerous longitudinal and cross-sectional studies indicate that, when compared with control groups, a lifetime history of ADHD is associated with problems with academic performance and attainment, occupational performance and employment status, relationship satisfaction, increased likelihood of health problems, likelihood of psychiatric comorbidity, emerging evidence of increased risk for suicide in complex cases (namely when ADHD coexists with a psychiatric diagnosis and substance use problems), and increased likelihood of negative, pessimistic outlooks and low self-concept. ${ }^{16-22}$

Despite the evidence that ADHD is a condition distinct from other psychiatric and neurodevelopmental disorders that affect adults, and that it is associated with impairments that can manifest in virtually any domain of adult life, it nonetheless can be a challenging condition to assess due to the fact that many of its characteristic symptoms are nonspecific.
That is, akin to the symptom of a fever in medical practice, while an abnormally high body temperature is a problematic symptom and one that warrants intervention, more information is needed to determine the root cause of the fever that is to be treated, be it influenza, an infection, or malaria. In terms of assessment of ADHD, continuing this medical metaphor, whereas fever reduction may be a desired outcome of intervention, there is the question as to whether this is an adequate measure of the effectiveness of treatment, as fever reduction may be attained without achieving remission of the underlying medical problem or improvement in well-being. Hence, accurate assessment and measurement strategies during treatment are needed to optimize outcomes.

A thorough evaluation of adult ADHD utilizing various assessment inventories and sources of information helps to improve diagnostic accuracy and reduce the likelihood of misdiagnosis. Most, if not all, of the structured interviews and inventories reviewed here can serve double duty as important components of a comprehensive diagnostic evaluation as well as a means for tracking treatment response in either clinical practice or research. ${ }^{23-25}$ However, the diverse types of inventories and the aspects of ADHD they measure represent different ways to monitor treatment, depending on the desired effects expected from particular interventions. ${ }^{26}$ For example, pharmacotherapy for adult ADHD often targets symptom reduction, psychosocial treatment targets functional changes in behavioral terms, such as reduced procrastination or increased use of time management skills, and both strive for overall reduction in life impairments and improved wellbeing and quality-of-life.

The goal of this paper is to review the current state of measures used in the diagnostic assessment and treatment monitoring of adult ADHD. For the sake of organization and clarity, a distinction will be made between the different types and formats of available tools to this end. The first section reviews structured clinical interviews that can be used to systematically review past and current symptoms of ADHD using DSM criteria. The second section provides a review of various symptom measures based on the official diagnostic criteria as defined by DSM-5. ${ }^{1}$ Seeing as the list of core symptoms of ADHD is unchanged from DSM fourth edition (DSM-IV), with the only changes being raised age of onset and lowered diagnostic threshold for adult symptoms for either presentation domain, structured interviews and inventories developed for DSM-IV can be adapted to these changes and still used. ${ }^{27}$ Although the effects of pharmacotherapy are not limited to symptom improvement, with a reduction in symptoms hopefully leading to downstream improvements 
in overall functioning, these symptom measures may be particularly relevant for tracking medication response.

The third section examines various inventories designed specifically for adults with ADHD that draw on the diagnostic criteria but also cast a wider net to assess for other common clinical issues described by ADHD adults. Seeing as ADHD is increasingly understood as a developmental problem associated with poor self-regulation across time, or executive dysfunction, the fourth section reviews executive function inventories. The fifth section reviews measures of functional status or quality of life, or how well individuals are managing the various demands and life roles they are facing in their daily lives or their life satisfaction. Lastly, other considerations with regard to assessing treatment response and definitions of meaningful change relevant to the aforementioned measures are discussed.

The overarching goal of this paper is to provide practicing clinicians and clinician researchers working with adult ADHD with an overview of current treatment-monitoring options that can be adapted to their professional settings and practices. Whereas pharmacotherapy can be considered to intervene at the symptom level, psychosocial treatments can be considered to intervene at the level of life functioning. That is, psychosocial treatments do not necessarily directly target symptom reduction, but rather promote the consistent use of various coping strategies with which to manage the effects of ADHD symptoms and associated features of daily life. Just as functional status measures can be used to track pharmacotherapy response, ADHD symptom measures can be used to track psychosocial treatment response, as they have in psychosocial treatment outcome studies, but the task is to have the right connection between the aims of treatment and a measure designed to assess how well those aims are being met.

\section{Structured diagnostic interviews}

Structured diagnostic interviews are more likely to be used during the initial diagnostic evaluation and augmented with many of the symptom and functional inventories. However, these structured interviews are very useful in systematically establishing the diagnosis of ADHD in adults, including evidence and course of onset and persistence, and as a means for blinded ratings of treatment response in outcome research. All of the interviews include modules specifically focusing on assessing symptoms of ADHD based on the DSM criteria, establishing age-of-onset and impairment criterion, as well as reviewing other important developmental, clinical, and functional data (Table 1).

\section{The Adult ADHD Clinical Diagnostic Scale (Adult ACDS) version I.2}

The Adult ACDS version $1.2^{28}$ comprises the 18 symptoms of ADHD as defined by the DSM. The scale is a clinicianadministered, semi-structured interview. There are agespecific prompts for assessing both current ADHD symptoms and childhood onset.

\section{ADHD Lifespan Functioning Interview (ALFI)}

The $\mathrm{ALFI}^{29}$ is a wide-ranging, structured interview that evaluates symptoms of ADHD using a 3-point scale of Never,

Table I Structured diagnostic interviews for adult ADHD

\begin{tabular}{|c|c|c|}
\hline Scale (availability) & Description & Key characteristics \\
\hline $\begin{array}{l}\text { The Adult ADHD Clinical Diagnostic Scale (Adult } \\
\text { ACDS) version I.2 (available from Lenard Adler, MD, } \\
\text { at adultADHD@med.nyu.edu) }{ }^{28}\end{array}$ & $\begin{array}{l}\text { Clinician-administered, } \\
\text { structured interview }\end{array}$ & $\begin{array}{l}\text { Based on DSM-IV criteria } \\
\text { Assesses childhood and current symptoms } \\
\text { and impairments }\end{array}$ \\
\hline $\begin{array}{l}\text { ADHD Lifespan Functioning Interview (ALFI) } \\
\text { (available from Psychology Services Limited at } \\
\text { www.psychology-services.uk.com) })^{29}\end{array}$ & $\begin{array}{l}\text { Clinician-administered, } \\
\text { structured interview }\end{array}$ & $\begin{array}{l}\text { Based on current ICD-I0 and DSM-5 criteria } \\
\text { Assesses various domains of life functioning } \\
\text { Serves as follow-up measure }\end{array}$ \\
\hline $\begin{array}{l}\text { Conners' Adult ADHD Diagnostic Interview for } \\
\text { DSM-IV (CAADID) (purchase from Multi-Health } \\
\text { Systems at www.mhs.com) })^{31}\end{array}$ & $\begin{array}{l}\text { Clinician-administered, } \\
\text { structured interview }\end{array}$ & $\begin{array}{l}\text { Based on DSM-IV criteria } \\
\text { Assesses childhood and current symptoms } \\
\text { and impairments }\end{array}$ \\
\hline $\begin{array}{l}\text { Diagnostic Interview of ADHD in Adults (DIVA) } \\
\text { version } 2.0 \text { (available from www.divacenter.eu) }{ }^{32}\end{array}$ & $\begin{array}{l}\text { Clinician-administered, } \\
\text { structured interview }\end{array}$ & $\begin{array}{l}\text { Based on DSM-IV criteria } \\
\text { Assesses childhood and current symptoms } \\
\text { and impairments }\end{array}$ \\
\hline $\begin{array}{l}\text { Structured Clinical Interview for DSM-5 (SCID-5) - } \\
\text { Adult ADHD Module (purchase from American } \\
\text { Psychiatric Association Publishing at www.appi.org) }\end{array}$ & $\begin{array}{l}\text { Clinician-administered, } \\
\text { structured interview }\end{array}$ & $\begin{array}{l}\text { Based on DSM- } 5 \text { criteria } \\
\text { Focuses on symptoms over the past } 6 \text { months with } \\
\text { confirmation of childhood emergence, cross-situational } \\
\text { symptoms, and impairments }\end{array}$ \\
\hline
\end{tabular}

Abbreviations: ADHD, attention-deficit/hyperactivity disorder; DSM-5, Diagnostic and Statistical Manual of Mental Disorders fifth edition; DSM-IV, DSM fourth edition; ICD-I0, International Classification of Diseases tenth edition. 
Sometimes, or Often. It includes a review of past and current family constellation, academic and occupational functioning, substance use, legal/arrest record, and antisocial behavior. The companion ALFI-2 is designed as a follow-up interview to assess these same domains since the initial interview. ${ }^{30}$

\section{Conners' Adult ADHD Diagnostic Interview for DSM-IV (CAADID)}

The CAADID ${ }^{31}$ includes Part I that is a patient history questionnaire that can be completed by patients or administered by interview. Part II is a structured assessment of ADHD. All 18 DSM symptoms are presented one at a time with both current evidence and childhood evidence of symptoms (with examples) reviewed for each. Evidence of age of onset and impairment is also documented. The CAADID is commonly used in research as a structured measure of ADHD.

\section{Diagnostic Interview of ADHD in Adults (DIVA) version 2.0}

The DIVA version $2.0^{32}$ presents a sequence of ADHD symptoms in a similar format as the CAADID. Each symptom is presented one after another, with each evaluated in terms of current evidence and childhood evidence, with developmentally appropriate exemplars of symptoms provided to the evaluator. Evidence for age of onset, impairment, and symptoms manifesting in multiple settings is also evaluated.

\section{Structured Clinical Interview for DSM-5 (SCID-5)}

ADHD in adulthood is discussed more explicitly in DSM-5 than in previous editions, although the core group of 18 symptoms remains unchanged. ${ }^{1}$ The main changes to the diagnosis pertaining to adults with ADHD are the inclusion of adult-appropriate exemplars of symptoms, raising the age-of-onset criterion to 12 years old, and reducing the diagnostic threshold to 5 symptoms from either the inattention or hyperactivity/impulsivity symptom domains. Consequently, the SCID-5 includes an adult ADHD module. ${ }^{33}$ The module begins with a screening item asking about general evidence of issues related to distraction or disorganization. If there is evidence of possible inattention symptoms, the evaluator proceeds through the list of symptoms for inattention, asking for examples of each endorsed symptom over the past 6 months. After completing the review of inattention symptoms, the evaluator asks about issues related to restlessness, and impatience. Again, if there is the suggestion that these symptoms are issues for the patient, the evaluator proceeds through the list of symptoms for hyperactivity/impulsivity over the past
6 months, including examples for each endorsed symptom. Symptoms are endorsed as either present $(+)$ or absent $(-)$ in terms of whether the respondent's difficulties in each area far exceed those of peers. After completing the symptom lists, there are queries related to age of onset, presence of symptoms in multiple settings, and evidence of impairment.

\section{ADHD symptom measures}

The assessment of the core symptoms of ADHD as defined by DSM-5 is a part of any "gold standard" diagnostic evaluation, providing a useful baseline measurement. ${ }^{1}$ Hence, these symptom ratings provide a useful and convenient means for monitoring subsequent treatment, particularly for medication response or any intervention geared towards symptom reduction. Most of the symptom checklists are still based on DSM-IV criteria but can be easily adapted for use with DSM-5 criteria by making the requisite adjustments to modified age-of-onset criterion (12 years old) and diagnostic thresholds for adult symptom endorsement (endorsement of 5 of 9 symptoms in either the inattentive or hyperactive/ impulsive symptom cluster). ${ }^{1,27}$ There is a good deal of overlap and agreement among ADHD symptom measures, which means that clinicians can select those that are most relevant to and conducive with their practice needs, not to mention simply developing one's own checklist based on the diagnostic criteria (Table 2). ${ }^{34}$

\section{ADHD Rating Scale 5 (ADHD-RS-5)}

The ADHD-RS- $5^{35}$ for children and adolescents represents a recent update of the ADHD-RS-IV, both of which can be easily adapted for use with adult patients. ${ }^{36}$ The scale can be used as a self-report questionnaire or can be administered by a clinician using prompts appropriate for adults. The scale comprises the 18 DSM symptoms that are rated on a 4-point scale from Never or Rarely to Very Often. Normative data for adult respondents are not available, but it is still a useful scale for tracking symptoms in terms of number and severity.

\section{Adult ADHD Self-Report Scale Symptom Checklist (ASRS)}

The $\mathrm{ASRS}^{37}$ comprises the list of 18 symptoms of ADHD, with the first 6 representing a useful subset of symptoms that can be used as an initial screening scale for ADHD. The reliability of the screening items is equivalent to that of the entire scale. Items are rated on a 5-point scale from Never to Very Often. There are shaded areas in the response columns that help to identify relevant symptom endorsements in addition to the total score derived from summing the responses. 
Table 2 Adult ADHD symptom rating and screening scales

\begin{tabular}{|c|c|c|}
\hline Scale (availability) & Description & Key characteristics \\
\hline $\begin{array}{l}\text { ADHD Rating Scale } 5 \text { (ADHD-RS-5) (purchase from } \\
\text { Guilford Press at www.guilford.com) }{ }^{35}\end{array}$ & $\begin{array}{l}\text { Symptom checklist typically } \\
\text { used for children, but can be } \\
\text { adapted by using adult prompts }\end{array}$ & $\begin{array}{l}\text { Based on DSM- } 5 \text { symptom criteria but adapted for } \\
\text { use with adults } \\
\text { Self-report or clinician-administered } \\
\text { 4-point rating }\end{array}$ \\
\hline $\begin{array}{l}\text { Adult ADHD Self-Report Scale Symptom Checklist } \\
\text { (ASRS) (available from New York University } \\
\text { Langone Medical Center at www.med.nyu.edu/ } \\
\text { psych/adhd-self-assessment-tools-and-information) }\end{array}$ & $\begin{array}{l}\text { Self-report symptom checklist } \\
\text { with subset of items used as a } \\
\text { screening tool }\end{array}$ & $\begin{array}{l}\text { Based on DSM-IV symptom criteria } \\
\text { First } 6 \text { items are a reliable screening tool } \\
\text { 4-point rating }\end{array}$ \\
\hline $\begin{array}{l}\text { Barkley Adult ADHD Rating Scale IV (BAARS-IV) } \\
\text { (purchase from Guilford Press at } \\
\text { www.guilford.com) })^{38}\end{array}$ & Norm-based symptom checklist & $\begin{array}{l}\text { Based on DSM-IV symptom criteria, includes } \\
\text { sluggish cognitive tempo module for adults } \\
\text { Includes childhood and adult symptom ratings } \\
\text { Offers both self- and other-report versions } \\
\text { 4-point rating }\end{array}$ \\
\hline $\begin{array}{l}\text { Barkley Quick-Check for Adult ADHD Diagnosis } \\
\text { (Barkley Quick-Check) (purchase from Jones \& } \\
\text { Bartlett Learning at www.jblearning.com })^{40}\end{array}$ & $\begin{array}{l}\text { Self-report or clinician- } \\
\text { administered symptom checklist }\end{array}$ & $\begin{array}{l}\text { 9-item scale based on empirically derived set } \\
\text { of symptoms } \\
\text { Used as a screen to determine presence or absence } \\
\text { of symptoms }\end{array}$ \\
\hline $\begin{array}{l}\text { Young ADHD Questionnaire (YAQ) and RATE } \\
\text { Scale (RATE) (available from Psychology Services } \\
\text { Limited at www.psychology-services.uk.com) })^{41}\end{array}$ & Norm-based symptom checklist & $\begin{array}{l}\text { I I 2-Item scale (YAQ) and 32-item brief version } \\
\text { (RATE) based on empirically derived set of items } \\
\text { Includes self- and informant-rating forms for both } \\
\text { YAQ and RATE scales }\end{array}$ \\
\hline
\end{tabular}

Abbreviations: ADHD, attention-deficit/hyperactivity disorder; DSM-5, Diagnostic and Statistical Manual of Mental Disorders fifth edition; DSM-IV, DSM fourth edition.

A benefit of this scale is that it is in the public domain and is readily available for use.

\section{Barkley Adult ADHD Rating Scale IV (BAARS-IV)}

The BAARS-IV ${ }^{38}$ includes separate forms for retrospective ratings of childhood symptoms of ADHD and current symptoms within the past 6 months. The child and adult symptoms forms comprise the DSM-IV symptoms of ADHD. ${ }^{27}$ The current symptoms form offers the added benefit of including a module for sluggish cognitive tempo, or what will likely be deemed concentration-deficit disorder. ${ }^{39}$ Symptoms are rated on a 4-point scale from Never or Rarely to Very Often. Normative data are available for both number of symptoms endorsed (with endorsement defined as being rated as occurring Often or Very Often) and total symptom severity rating score for the different symptoms clusters. There are self- and other-report versions of the checklists allowing clinicians to obtain corroborative ratings for both childhood and adult scales.

\section{Barkley Quick-Check for Adult ADHD Diagnosis}

The Barkley Quick-Check ${ }^{40}$ form includes a single list of 9 symptoms of ADHD empirically derived from a study of adults seeking evaluation through an adult ADHD clinic and compared with clinical and community controls. ${ }^{10}$ This scale uses only a few symptoms that overlap with DSM criteria and includes some items that do not appear in DSM criteria. Used as a screening instrument, symptoms are endorsed as either Yes or No, but a clinician could easily adapt it to be a 4- or 5-point rating scale as a follow-up measure that could be an adjunct measure used with aforementioned DSM-based measures. There are no normative data for individual scores but, as the list was empirically-derived, sensitivity and specificity data support the use of these 9 symptoms.

\section{Young ADHD Questionnaire (YAQ) and RATE Scale (RATE)}

The YAQ is a 112-item scale that represents another empirically derived set of items not limited to DSM criteria (the RATE is a shorter version of the YAQ).$^{41}$ Items are rated on an 8-point scale from Not at All to Most of the Time. The YAQ casts a wider net in terms of including factors associated with ADHD, such as modules for emotional control, antisocial behavior, and social functioning in addition to ADHD symptoms. There are both self- and informant-rating forms for both the YAQ and RATE scales. In addition to being briefer ( 32 items), a benefit of the RATE is that it is readily available in the public domain.

\section{Adult ADHD inventories}

In addition to including most if not all of the ADHD symptom criteria, adult ADHD inventories have the added benefit of 
Table 3 Adult ADHD inventories

\begin{tabular}{|c|c|c|}
\hline Scale (availability) & Description & Key characteristics \\
\hline Brown Attention Deficit Disorders Scales - Adult & 40-item inventory & Can be used as self-report or interview \\
\hline Version (BADDS) (purchase from Pearson at & Norm-based & Area to record observer ratings \\
\hline \multirow[t]{2}{*}{ www.pearsonclinical.com $)^{42}$} & & Based on Brown's executive function model \\
\hline & & 4-point rating \\
\hline Conners' Adult ADHD Rating Scales (CAARS) & Norm-based, self-report symptom & Screener, short, and long versions \\
\hline (purchase from Multi-Health Systems at & checklist & \\
\hline \multirow[t]{3}{*}{ www.mhs.com $)^{44}$} & Screener, short, and long versions & Observer rating forms available \\
\hline & Observer rating forms available & Gender and age norms \\
\hline & & 4-point rating \\
\hline Wender-Reimherr Adult Attention & 28-Item, clinician-rated symptom & Original versions of this scale had been developed \\
\hline Deficit Disorder Scale (WRAADDS) & checklist & before recent DSM criteria \\
\hline (contact: Fred W Reimherr, MD, at & Includes items/prompts related to & This scale has been used as a measure of change \\
\hline fred.reimherr@hsc.utah.edu) ${ }^{45}$ & 7 clinically relevant domains in & in clinical trials and can be used to guide clinician \\
\hline & addition to DSM-related criteria & ratings or to develop a score by tabulating responses \\
\hline
\end{tabular}

Abbreviations: ADHD, attention-deficit/hyperactivity disorder; DSM, Diagnostic and Statistical Manual of Mental Disorders.

addressing clinically relevant issues beyond the common symptoms of hyperactivity, impulsivity, and inattention. The issues may include a wider range of presenting problems, such as disorganization, poor time management, difficulties with reading, as well as problems related to self-esteem, sleep, and emotional management. Consequently, it is often useful to track changes in these problem areas throughout treatment (Table 3).

\section{Brown Attention Deficit Disorders Scales - Adult Version (BADDS)}

The $\mathrm{BADDS}^{42}$ is a 40 -item inventory that assesses a variety of symptoms of ADHD contextualized in real-life scenarios, such as items pertaining to the need to re-read text, losing focus in conversations, and having difficulties organizing and getting started on tasks. It can be administered by self-report or by clinician interview. Items are rated on a 4-point scale from Never to Almost Daily, and there is a section for corroborative ratings of each item, although there are no norms for these corroborative ratings. The BADDS yields a total score and 5 clinically useful subscale scores representing Brown's categories of executive functioning. ${ }^{43}$ The actual inventory is a self-score form which allows the clinician to calculate raw scores and place them on a profile form that provides $T$-scores for the total score and each subscale score.

\section{Conners' Adult ADHD Rating Scales (CAARS)}

The CAARS ${ }^{44}$ is a self-report inventory that assesses a range of symptoms of ADHD in adults. There is a screening version, a brief version (comprising solely DSM categories), and a long version (that includes several useful factor-based subscales apart from DSM subscales). There are self- and other-rating versions with normative data for each scale. Similar to the BADDS, the CAARS is a self-score inventory that provides separate profile forms for males and females as well as providing age-based norms. The CAARS also offers an inconsistency index that is used to identify notable variations in responses to items measuring similar symptoms or factors that warrant follow-up in terms of the validity of these responses.

\section{Wender-Reimherr Adult Attention Deficit Disorder Scale (WRAADDS)}

The WRAADDS ${ }^{45}$ is a 28 -item clinician-rated scale that draws on the Utah criteria for ADHD adapted to adults that had been under development well before recent editions of the DSM. Clinicians rate each item on a 3-point scale of Not Present, Mild, or Clearly Present. There are 7 symptom domains that result in a 5-point summary rating of severity from None to Very Much. The WRAADDS might be particularly helpful in discerning evidence of emotional regulation problems and other clinically relevant factors beyond the extant diagnostic criteria. The scale has been used in clinical trials as a measure of change.

\section{Executive functioning inventories}

Although symptom ratings are an essential component of an initial evaluation and follow-up measurements, the list of 18 symptoms outlined in DSM-5 often does not capture the difficulties described by patients. ${ }^{1}$ The adult ADHD inventories described earlier often include measures of core symptoms but expand their coverage to include examples related to disorganization, procrastination, time management, 
and emotional regulation difficulties, some more than others. Many of these areas of difficulty are consistent with the view that ADHD can be understood as a developmental disorder of impaired executive functions. ${ }^{10,11}$ The executive functions can be understood as those self-directed behaviors that constitute self-regulation or that underlie the ability to develop and follow through on goal-directed plans to improve one's future outcomes. ${ }^{46}$ Self-report measures of these executive functions have been found to be a reliable diagnostic indicator of adult ADHD, including better measures of impairment than tests purporting to measure executive functions, although most executive function symptoms are not represented in the official diagnostic criteria. ${ }^{10,11}$ Although not specific, ADHD can be considered a developmental syndrome of executive dysfunction, whereas other conditions, such as major depression, can be associated with reduced executive functioning during a mood episode that improves as mood normalizes. Nevertheless, the following scales can be useful in assessing and tracking executive functioning in cases of ADHD, which may be particularly useful in tracking the effects of psychosocial treatment focused on developing and implementing coping strategies for these difficulties. ${ }^{47,48}$ It should be noted that the BADDS, reviewed in the "Adult ADHD inventories" section, can also be considered an executive functioning measure insofar as it is based on Brown's executive function model of ADHD (Table 4). ${ }^{42,43}$

\section{Barkley Deficits in Executive Functioning Scale for Adults (BDEFS)}

The BDEFS ${ }^{49}$ is a norm-based assessment of executive functioning. There are short and long versions of the scale with both self- and observer-report versions. Respondents rate each item on a 4-point scale from Never/Rarely to Very Often. Scores for each of 5 executive function domains and an overall executive function score are calculated. There is also a specific ADHD-EF Index score derived from items characteristic of adults with ADHD that provides an indication of risk for ADHD. There are age- and gender-based norms.

\section{Behavior Rating Inventory of Executive Function - Adult (BRIEF-A)}

The BRIEF- $\mathrm{A}^{50}$ is an 80 -item, norm-based, self-report inventory on which the respondent rates a variety of items measuring executive functioning on a 3-point scale (Never, Sometimes, or Often). There is also an observer version of the inventory. There are 9 subscale scores that are components of overarching index scores for either behavioral regulation or metacognition, and there is a global executive composite score. There are also Negativity, Inconsistency, and Infrequency Scales, which serve as measures of the validity of responses.

\section{Functional impairment/quality-of- life inventories}

Although a core element of the diagnosis, the requirement for impairment associated with the core symptoms of ADHD is difficult to quantify. There may be obvious problems associated with ADHD that are clinically elevated in adult ADHD and executive functioning inventories that make a direct and causal contribution to functioning problems in various adult roles that warrant treatment. In many cases, it can be useful to have separate measures of functioning and/or quality of life to illustrate the effects of ADHD on one's life and to justify the need for treatment (Table 5).

\section{Adult ADHD Quality-of-Life Scale (AAQoL)}

The AAQoL ${ }^{51}$ is a 29 -item, self-report measure of functioning in a variety of life domains and adult roles. Items are rated on a 5-point scale that are transformed into a 0-100 scale, with higher scores reflecting higher quality of life. Scores are calculated for Life Productivity, Psychological Health, Life Outlook, and Relationships, in addition to a Total score.

\section{Barkley Functional Impairment Scale (BFIS)}

The BFIS ${ }^{52}$ provides a norm-based measure of functioning and impairments that is not specific to ADHD. The BFIS is

Table 4 Executive functioning inventories

\begin{tabular}{|c|c|c|}
\hline Scale (availability) & Description & Key characteristics \\
\hline Barkley Deficits in Executive Functioning Scale & Norm-based, self-report inventory & 89-item long form, 20-item short form \\
\hline for Adults (BDEFS) (purchase from Guilford & of executive functions & Observer forms available \\
\hline \multirow[t]{2}{*}{ Press at www.guilford.com $)^{49}$} & & Includes ADHD-executive functioning index \\
\hline & & Includes 5 domains of executive functioning with 4-point rating \\
\hline Behavior Rating Inventory of Executive & Norm-based, self-report inventory & 80-item inventory \\
\hline Function - Adult (BRIEF-A) (purchase & assessing executive functions & Observer forms available \\
\hline from PAR at www4.parinc.com $)^{50}$ & & Includes 3 scales, 9 subscale scores, and 3 validity scales \\
\hline
\end{tabular}

Abbreviation: ADHD, attention-deficit/hyperactivity disorder. 
Table 5 Functional impairment/quality-of-life scales

\begin{tabular}{|c|c|c|}
\hline Scale (availability) & Description & Key characteristics \\
\hline $\begin{array}{l}\text { Adult ADHD Quality-of-Life Scale (AAQoL) } \\
\text { (available from Brod et al) })^{57}\end{array}$ & Self-report inventory of quality of life & $\begin{array}{l}\text { 29-item scale, 5-point rating } \\
\text { Evaluates } 4 \text { domains of well-being and overall } \\
\text { quality of life }\end{array}$ \\
\hline $\begin{array}{l}\text { Barkley Functional Impairment Scale (BFIS) } \\
\text { (purchase from Guilford Press at www.guilford.com) })^{52}\end{array}$ & $\begin{array}{l}\text { Norm-based, self-report rating scale of } \\
\text { impairment in different life domains }\end{array}$ & $\begin{array}{l}\text { Observer-report forms available } \\
\text { Evaluates } 15 \text { domains of adult life, mean } \\
\text { impairment score ( } 10 \text {-point rating for each } \\
\text { domain), and percentage of impaired domains }\end{array}$ \\
\hline $\begin{array}{l}\text { Weiss Functional Impairment Rating Scale (WFIRS) } \\
\text { (available from Weiss) }^{53}\end{array}$ & Self-report rating scale of life impairment & $\begin{array}{l}\text { 64-item scale, 4-point rating } \\
\text { Evaluates } 6 \text { domains of life (including self-concept) } \\
\text { and overall impairment }\end{array}$ \\
\hline
\end{tabular}

a 15-item, self-report inventory that also offers an observerreport form. Each item is associated with a specific life domain. Items are rated by respondents on a 10-point scale of severity of difficulties from Not at All to Severe (as well as Does Not Apply if the domain is not relevant and thus is not included in the scoring). Total scores are calculated for each of 15 life domains (or however many apply to an individual) and compared with age- and gender-based norms. There is also a Mean Impairment score and a Percent Domains Impaired score, the latter reflecting the percentage of the domains relevant to the individual that exceeded the threshold for impairment.

\section{Weiss Functional Impairment Rating Scale (WFIRS)}

The WFIRS ${ }^{53}$ is a 64-item, self-report scale that also has an observer-report form. Items are rated by respondents on a 10-point scale from Not at All to Severe, with an additional Does Not Apply option that is not calculated if it is endorsed. Subscale scores for the life domains of Family, Work, School, Life Skills, Self-Concept, Social, and Risk are calculated, as is a Total Impairment score.

\section{Selecting and using interviews, measures, and inventories Guiding principles}

The aforementioned diagnostic and treatment-monitoring interviews and scales represent a range of clinical tools that are helpful (if not essential in some cases) for clinicians who assess and treat patients with adult ADHD. However, as with other tools, how they are used affects the outcomes achieved.

The primary guiding principle and caution is that the diagnostic and clinical data gathered from the use of these tools cannot be taken at face value and must be considered as one component of the overall clinical picture. For example, an individual may present with elevated scores on a screening measure of adult ADHD or an adult ADHD inventory. However, additional inquiry about or use of screening measures for depression might indicate that the "attention" issues are actually a symptom of a current mood episode (or comorbid ADHD and depression). Many symptoms of ADHD overlap with other psychiatric and medical conditions. The complex cases do not negate the information obtained from the adult ADHD measures - in the case mentioned, the depressed patient endorsing poor concentration is providing accurate information, but it simply may not reflect ADHD. Clinical diligence is required to gather and consider all the available information for diagnosis and treatment.

A related principle, particularly for establishing an accurate diagnosis, is not relying on the results from any single measure without gathering more information. The structured diagnostic interviews build in the different components of making the diagnosis, including confirming the presence of symptoms, getting specific examples of them, and that these symptoms appear in more than 1 setting and directly result in impairment. The combination of self- and observer-report offers diverse sources of information. A clinician reviewing a patient's responses on an adult ADHD inventory used to monitor treatment, asking for specific examples of persistent difficulties or treatment gains, helps to sort through the data and make sure it is clear and meaningful.

\section{Screening}

Following up on the previous section, screening scales offer a thin slice of functioning that guides further inquiry or assessment. There are truncated versions of many of the symptom measures and inventories that serve as useful screening tools to probe whether more extensive inquiry about possible ADHD is required. Several screening scales are in the public domain and readily available. DSM-related symptom checklists are very practical with the caution that many of the symptoms are nonspecific and may be associated with other conditions. On the other hand, there is no 
prohibition on using full inventories as an initial screening measure, particularly if a patient's presenting issues are highly indicative of possible ADHD.

\section{Diagnosis}

Be it to establish the diagnosis of ADHD as part of a new patient evaluation in private practice to establish a treatment plan or as part of a comprehensive evaluation and report, a diagnosis of ADHD based on DSM criteria is part of a "gold standard" evaluation. The structured diagnostic interviews address all of the diagnostic criteria, including assessing each symptom (past and present), eliciting examples, and criteria for onset, multiple settings, and impairment. These structured interviews are often used in research programs to establish the diagnosis and by adult ADHD specialty clinics as part of their evaluation process. In standard clinical practice, clinicians may perform modified versions of these interviews, guided by self- and other-report symptom checklists. Several adult ADHD inventories include DSM-related symptoms and subscales as well as additional subscales that assess for a wider array of clinical features of ADHD. These norm-based inventories add diagnostic credibility to the evaluation. Impairment measures are used in evaluations in which documentation of the degree of impairment associated with ADHD (or any other condition) is required.

\section{Treatment planning and monitoring}

In addition to the role they play in the diagnostic evaluation, DSM symptom checklists can also be used to plan and monitor treatment, particularly pharmacotherapy that targets symptom improvement. Although not required to establish the diagnosis of ADHD, measures of executive functioning and/or quality of life shed light on many of the areas of coping difficulty experienced by ADHD adults that are often the targets of psychosocial treatment. Although symptom checklists are frequently used to track psychosocial treatment due to their availability, executive functioning inventories are likely a more accurate measure of psychosocial outcomes. It may be that short versions of various measures readministered throughout treatment are convenient enough for patients to complete and provide adequate data to assess treatment response.

\section{Other considerations Observer reports and other collateral information}

The use of observer ratings and other collateral information is strongly encouraged during the diagnostic evaluation process for ADHD. ${ }^{1,25}$ Similarly, it can be useful using collateral ratings as a measure of treatment response.

Most of the inventories reviewed in this paper include either separate observer rating forms or space on the inventory to record the impressions of those who know the patient. For that matter, any symptom checklist can easily be used to catalog the observations of those who know the patient who is undergoing an assessment or treatment. There may be some items that are difficult for another person to observe, such as inattention or reading comprehension, but seeking these collateral reports is often very helpful, including sources that observe the patient's functioning in different roles or domains of life.

In many cases, a patient may not have someone who can provide informed observations of day-to-day difficulties, because the patient lives alone, or friends and family do not have the opportunity to observe academic or workplace behavior, or the patient does not wish to disclose their evaluation and/or treatment. Having an observer who can only provide impressions of the patient in even 1 domain of the patient's life is a useful resource. Thus, a partner or a roommate who lives with the patient and sees her or him function at home will have a different view of the patient than a coworker or fellow student. Discrepancies in these reports do not automatically call into question their validity but rather provide wider coverage in terms of observations of functioning in diverse settings.

From an initial diagnostic standpoint, old assessment reports, grade reports, teacher comments, legal records, or other collateral information provides a "paper trail" of symptoms and functioning in different settings. Even though no one piece of information is diagnostic, a tapestry of behaviors across time and across settings (or lack thereof) provides useful information in order to increase diagnostic accuracy. In terms of monitoring treatment response, real-world collateral information, such as performance evaluations at work, grade reports, attendance records, and being removed from (or placed on) workplace or academic probation, among others, offers helpful, real-world measures of progress.

\section{Degrees of "clinically meaningful" change}

In addition to these quantified measures, patients often have their own metrics for their treatment response. Simply asking patients if they have noticed any differences since starting treatment, either medical or psychosocial, often yields useful information. Although difficult to compute, patients often describe experiences such as being better able to focus on reading, noticing distractions without breaking their focus on a task, maintaining a habit of placing their keys and cell 
phone in a predetermined spot, or numerous other personally salient signs of progress. The impressions of significant others who are invited to a clinical session can be very helpful, as sometimes they observe improvements that patients do not. In 1 case, during a psychosocial treatment session attended by the patient's wife, the therapist asked the patient about his response to medications, with the patient having just finished his first month taking a prescribed medication for ADHD. The patient said that he did not think the medication was helpful and had not refilled the prescription since it ran out the previous week. His wife immediately spoke up, observing that she thought the patient had been more focused at home and less impulsive, but he had seemed to backslide during what turned out to be the very time he had stopped taking his medications. Various other markers for treatment response might also be consistent with treatment goals, such as on-time arrival for class or work, fewer late fees for bills, completing projects without needing extensions, and so forth.

\section{Reliable change}

Of course, the readministration of self-report adult ADHD inventories and symptom checklists, executive function inventories, and/or impairment/quality-of-life rating scales provide follow-up scores that can be compared with baseline scores to gauge treatment response. Structured diagnostic interviews are probably too time- and labor-intensive for repeated use in clinical practice and are usually employed in research as a means for blinded follow-up ratings.

However, is mere improvement of a few points on a scale an adequate measure of treatment response? There may be different targets for different measures as well as different markers at different points of treatment. For example, after a month of treatment, a patient might show a 10-point improvement on one of the adult ADHD inventory subscales, but this score might still fall in the clinical range. In terms of symptom ratings, there may be similar types of improvements, perhaps even falling in a subthreshold range, but the symptoms still create functional problems. In some cases, these improvements in the midst of ongoing symptoms and impairments reflect the reality of treatment of adult ADHD inasmuch as the disorder can create such pervasive and severe difficulties in life functioning that it takes time and ongoing treatment, be it medical, psychosocial, or a combination of these and other supports, to take hold and undo the effects of longstanding ADHD. Thus, improvements are desired, but treatment to remission (and optimal functioning) is the ultimate goal. ${ }^{54}$

Some of the scales reviewed in previous sections provide measures of Reliable Change Index (RCI) ${ }^{55}$ The RCI calculates the pre- and posttest difference thresholds for reliable change that is likely to occur by chance $5 \%$ of the time or less. These scales include tables with the difference scores for RCI by different age groups for different scales..$^{38,49,52}$ Similarly, an 8-point difference on the AAQoL was found to be the minimally clinically important difference in quality-of-life scores between baseline and follow-up. ${ }^{56}$

Seeing as many of the adult ADHD symptom ratings and most of the adult ADHD inventories provide normative data, these norms can also serve as a good measure of treatment response. That is, the conventional threshold for "clinical elevation" on such measures is typically 1.5 or 2.0 standard deviations above the mean, or at the 93rd or 98th percentile, respectively. Falling below these "elevations" can be considered as falling in the nonclinical range or as a broad threshold for defining "normalization". Follow-up scores falling within 1.0 standard deviation of the normal mean is an even more convincing threshold for normalization. Other solutions involve calculating percentage markers of improvements, such as $30 \%$ reduction in symptoms, which is a metric often used in clinical trials. . $^{38,49,52}$

\section{Summary}

The goal of this article was to review the various options that practicing clinicians can use to aid the diagnostic assessment and monitoring of psychosocial and medical treatment of ADHD in adult patients. There are a variety of structured interviews, DSM-based symptom inventories and screening scales, adult ADHD inventories, as well as measures of executive functions, and impairments/quality of life from which clinicians can select diagnostic and treatment-monitoring scales suited to their practice needs. These measures can be used as part of a diagnostic assessment with specific scales used to serve as follow-up measures of treatment response. The specific scales used to monitor treatment can be tailored to the type of treatment provided, namely symptom checklists for pharmacotherapy, executive functioning inventories for psychosocial treatment, and adult ADHD inventories (that often include both symptoms and related features) and life impairment ratings for both types of treatments. Some clinicians may devise their own scales to focus on the specific problems reported by patients. Ultimately, the use of these inventories as part of a thorough evaluation to increased diagnostic accuracy, and as tools with which to monitor personalized treatments, helps to provide relevant information with which to inform adjustments in a treatment plan and/or encourage referrals for adjunctive treatments in order to increase the likelihood that adult patients with ADHD will experience notable and sustained improvements in functioning and well-being. 


\section{Disclosure}

The author reports no disclosures or conflicts of interest relevant to the topic of this manuscript.

\section{References}

1. American Psychiatric Association. Diagnostic and Statistical Manual of Mental Disorders. 5th ed. Arlington: American Psychiatric Association; 2013.

2. Polanczyk G, de Lima MS, Horta BL, Biederman J, Rohde LA. The worldwide prevalence of ADHD: a systematic review and metaregression analyses. Am J Psychiatry. 2007;164(6):942-948.

3. Fayyad J, De Graaf R, Kessler R, et al. Cross-national prevalence and correlates of adult attention-deficit hyperactivity disorder. $\mathrm{Br} J$ Psychiatry. 2007;190:402-409.

4. Kessler RC, Adler L, Barkley R, et al. The prevalence and correlates of adult ADHD in the United States: results from the National Comorbidity Survey Replication. Am J Psychiatry. 2006;163(4):716-723.

5. Kessler RC, Adler LA, Barkley R, et al. Patterns and predictors of attention-deficit/hyperactivity disorder persistence into adulthood: results from the national comorbidity survey replication. Biol Psychiatry. 2005;57(11):1442-1451

6. Sibley MH, Swanson JM, Arnold LE, et al. Defining ADHD symptom persistence in adulthood: optimizing sensitivity and specificity. $J$ Child Psychol Psychiatry. Epub 2016 Sep 19.

7. Faraone SV, Biederman J, Mick E. The age-dependent decline of attention deficit hyperactivity disorder: a meta-analysis of follow-up studies. Psychol Med. 2006;36(2):159-165.

8. American Psychiatric Association. Diagnostic and Statistical Manual of Mental Disorders. 2nd ed. Washington: American Psychiatric Association; 1968.

9. Barkley RA, Fischer M, Smallish L, Fletcher K. The persistence of attention-deficit/hyperactivity disorder into young adulthood as a function of reporting source and definition of disorder. J Abnorm Psychol. 2002;111(2):279-289.

10. Barkley RA, Murphy KR, Fischer M. ADHD in Adults: What the Science Says. New York: Guilford Press; 2008.

11. Kessler RC, Green JG, Adler LA, et al. Structure and diagnosis of adult attention-deficit/hyperactivity disorder: analysis of expanded diagnostic criteria from the Adult ADHD Clinical Diagnostic Scale. Arch Gen Psychiatry. 2010;67(11):1168-1178.

12. Moffitt TE, Houts R, Asherson P, et al. Is adult ADHD a childhoodonset neurodevelopmental disorder? Evidence from a four-decade longitudinal cohort study. Am J Psychiatry. 2015;172(10):967-977.

13. Caye A, Rocha TB, Anselmi L, et al. Attention-deficit/hyperactivity disorder trajectories from childhood to young adulthood: evidence from a birth cohort supporting a late-onset syndrome. JAMA Psychiatry. 2016;73(7):705-712.

14. Agnew-Blais JC, Polanczyk GV, Danese A, Wertz J, Moffitt TE, Arseneault L. Evaluation of the persistence, remission, and emergence of attention-deficit/hyperactivity disorder in young adulthood. JAMA Psychiatry. 2016;73(7):713-720.

15. Faraone SV, Biederman J. Can attention-deficit/hyperactivity disorder onset occur in adulthood? JAMA Psychiatry. 2016;73(7):655-656.

16. Barbaresi WJ, Colligan RC, Weaver AL, Voigt RG, Killian JM, Katusic SK. Mortality, ADHD, and psychosocial adversity in adults with childhood ADHD: a prospective study. Pediatrics. 2013;131(4): 637-644.

17. Biederman J, Faraone SV, Spencer TJ, Mick E, Monuteaux MC, Aleardi M. Functional impairments in adults with self-reports of diagnosed ADHD: a controlled study of 1001 adults in the community. J Clin Psychiatry. 2006;67(4):524-540.

18. Brook JS, Brook DW, Zhang C, Seltzer N, Finch SJ. Adolescent ADHD and adult physical and mental health, work performance, and financial stress. Pediatrics. 2013;131(1):5-13.

19. Galéra C, Bouvard MP, Lagarde E, et al. Childhood attention problems and socioeconomic status in adulthood: 18-year follow-up. $\mathrm{Br} J$ Psychiatry. 2012;201(1):20-25.
20. Klein RG, Mannuzza S, Olazagasti MA, et al. Clinical and functional outcome of childhood attention-deficit/hyperactivity disorder 33 years later. Arch Gen Psychiatry. 2012;69(12):1295-1303.

21. Hechtman L, Swanson JM, Sibley MH, et al; MTA Cooperative Group. Functional adult outcomes 16 years after childhood diagnosis of attention-deficit/hyperactivity disorder: MTA results. $J$ Am Acad Child Adolesc Psychiatry. 2016;55(11):945-952.e2.

22. Roy A, Hechtman L, Arnold LE, et al; MTA Cooperative Group. Childhood factors affecting persistence and desistance of attention-deficit/ hyperactivity disorder symptoms in adulthood: results from the MTA. J Am Acad Child Adolesc Psychiatry. 2016;55(11):937-944.

23. Goodman DW. ADHD in adults: update for clinicians on diagnosis and assessment. Prim Psychiatry. 2009;16(11):21-30.

24. Surman CBH. Clinical assessment of ADHD in adults. In: Surman $\mathrm{CBH}$, editor. ADHD in Adults: A Practical Guide to Evaluation and Management. New York: Springer; 2013:19-44.

25. Ramsay JR. Psychological assessment of adults. In: Barkley RA, editor. Attention-Deficit Hyperactivity Disorder: A Handbook for Diagnosis and Treatment. 4th ed. New York: Guilford Press; 2014:475-500.

26. Adamo N, Seth S, Coghill D. Pharmacological treatment of attentiondeficit/hyperactivity disorder: assessing outcomes. Expert Rev Clin Pharmacol. 2015;8(4):383-397.

27. American Psychiatric Association. Diagnostic and Statistical Manual of Mental Disorders. 5th ed. Washington: American Psychiatric Association; 1994.

28. Adler L, Spencer T. The Adult ADHD Clinical Diagnostic Scale (ACDS) V 1.2. New York: New York University School of Medicine; 2004.

29. Young S. Adult Lifespan Functioning Interview (ALFI). Psychology Services Ltd. Available from: www.psychology-services.uk.com. Accessed November 19, 2016.

30. Young S. Adult Lifespan Functioning Interview Follow Up (ALFI-2). Psychology Services Ltd. Available from: www.psychologyservices.uk.com. Accessed November 19, 2016.

31. Epstein J, Johnson DE, Conners CK. Conners' Adult ADHD Diagnostic Interview for DSM-IV. North Tonawanda: Multi-Health Systems; 2001.

32. Kooij JJS, Francken MH. Diagnostic Interview of ADHD in Adults. Version 2.0 (DIVA). Hague: DIVA Foundation; 2010.

33. First MB, Williams JBW, Karg RS, Spitzer RL. Structured Clinical Interview for DSM-5 Disorders: Clinician Version (SCID-5-CV). Arlington: American Psychiatric Association; 2016.

34. Rodriguez PD, Simon-Dack SL. Factor analysis of five adult ADHD self-report measures: are they all the same? J Atten Disord. 2013; 17(1):64-69.

35. DuPaul GJ, Power TJ, Anastopoulos AD, Reid R. ADHD Rating Scale-5 for Children and Adolescents: Checklists, Norms, and Clinical Interpretation. New York: Guilford Press; 2016.

36. DuPaul CJ, Power TJ, Anastopoulos AD, Reid R. ADHD Rating Scale-IV for Children and Adolescents: Checklists, Norms, and Clinical Interpretation. New York: Guilford Press; 1998.

37. Adler LA, Kessler RC, Spencer T. Adult SelfReport Scale. ASRS-V1.1. New York: World Health Organization; 2003.

38. Barkley RA. Barkley Adult ADHD Rating Scale-IV (BAARS-IV). New York: Guilford Press; 2011.

39. Barkley RA. Distinguishing sluggish cognitive tempo from attention-deficit/hyperactivity disorder in adults. J Abnorm Psychol. 2012;121(4):978-990.

40. Barkley RA. Barkley Quick Check for Adult ADHD Diagnosis. Sudbury: Jones and Bartlett Learning; 2009.

41. Young S. The YAQ-S and YAQ-I: the development of self and informant questionnaires reporting on current adult ADHD symptomatology, comorbid, and associated problems. Pers Individ Dif. 2004;36(5):1211-1223.

42. Brown TE. Brown Attention-Deficit Disorder Scales. San Antonio: The Psychological Corporation; 1996.

43. Brown TE. A New Understanding of ADHD in Children and Adults. Executive Function Impairments. New York: Routledge; 2013.

44. Conners CK, Erhardt D, Sparrow E. Conners' Adult ADHD Rating Scales: Technical Manual. North Tonawanda: Multi-Health Systems; 1999. 
45. Marchant BK, Reimherr FW, Robison D, Robison RJ, Wender PH. Psychometric properties of the Wender-Reimherr Adult Attention Deficit Disorder Scale. Psychol Assess. 2013;25(3):942-950.

46. Barkley RA. Executive Functions: What They Are, How They Work, and Why They Evolved. New York: Guildford Press; 2012.

47. Solanto MV. Cognitive-Behavioral Therapy for Adult ADHD: Targeting Executive Dysfunction. New York: Guildford Press; 2011.

48. Ramsay JR, Rostain AL. Cognitive-Behavioral Therapy for Adult ADHD: An Integrative Psychosocial and Medical Approach. 2nd ed. New York: Routledge; 2015.

49. Barkley RA. Barkley Deficits in Executive Functioning Scale (BDEFS). New York: Guilford Press; 2011.

50. Roth RM, Isquith PK, Gioia GA. BRIEF-A: Behavior Rating Inventory of Executive Function - Adult Version. Lutz: Psychological Assessment Resources Inc.; 2005.

51. Brod M, Johnston J, Able S, Swindle R. Validation of the adult attentiondeficit/hyperactivity disorder quality-of-life scale (AAQoL): a diseasespecific quality-of-life measure. Qual Life Res. 2006;15(1):117-129.
52. Barkley RA. Barkley Functional Impairment Scale for Adults (BFIS for Adults). New York: Guilford Press; 2011.

53. Weiss MD. The unique aspects of assessment of adult ADHD. Prim Psychiatry. 2010;17(5):21-25.

54. Rostain A, Jensen PS, Connor DF, Miesle LM, Faraone SV. Toward quality care in ADHD: defining the goals of treatment. J Atten Disord. 2015; 19(2):99-117.

55. Jacobson NS, Truax P. Clinical significance: a statistical approach to defining meaningful change in psychotherapy research. J Consult Clin Psychol. 1991;59(1):12-19.

56. Tanaka Y, Brod M, Lane JR, Upadhyaya H. What is a clinically relevant improvement in quality of life in adults with ADHD? J Atten Disord. Epub 2015 Apr 15.

57. Brod M, Perwien A, Adler L, Spencer T, Johnston J. Conceptualization and assessment of quality of life for adults with attention-deficit/ hyperactivity disorder. Prim Psychiatry. 2005;12(6):58-64.
Neuropsychiatric Disease and Treatment

\section{Publish your work in this journal}

Neuropsychiatric Disease and Treatment is an international, peerreviewed journal of clinical therapeutics and pharmacology focusing on concise rapid reporting of clinical or pre-clinical studies on a range of neuropsychiatric and neurological disorders. This journal is indexed on PubMed Central, the 'PsycINFO' database and CAS,

\section{Dovepress}

and is the official journal of The International Neuropsychiatric Association (INA). The manuscript management system is completely online and includes a very quick and fair peer-review system, which is all easy to use. Visit http://www.dovepress.com/testimonials.php to read real quotes from published authors. 